\title{
Erratum to: Effects of Bolting and Flower Stem Removal on the Growth and Chemical Qualities of Onion Bulbs
}

\author{
Young Seok Kwon ${ }^{1}$, Cheol Woo Kim ${ }^{1}$, Jiseon $\mathrm{Kim}^{2}$, JinSeong $\mathrm{Moon}^{3}$, and Kil Sun $\mathrm{Yoo}^{2 *}$ \\ ${ }^{I}$ Vegetable Crop Division, National Institute of Horticultural \& Herbal Science, \\ Rural Development Administration, Muan 534-833, Korea \\ ${ }^{2}$ Department of Horticulture and Life Sciences, Yeungnam University, Gyeongsan 712-749, Korea \\ ${ }^{3}$ Onion Research Institute, Gyeongnam Agricultural Research and Extension Services, Changnyeong 635-821, Korea \\ *Corresponding author: ksyoo@ynu.ac.kr
}

(C) Korean Society for Horticultural Science and Springer 2016

Erratum to: Hortic. Environ. Biotechnol. 57(2):132-138. 2016.

DOI 10.1007/s13580-016-0116-7

The original online version of this article contained an error in the third author's name.

The correct name of the author should be given as Jiseon Kim not Ji Sun Kim.

The online version of the original article can be found under doi:10.1007/s13580-016-0116-7. 